\title{
Asociacionismo de mujeres inmigrantes en el País Vasco: actuaciones y desafíos
}

\author{
Amaia Unzueta Sesumaga \\ Kambotik Consultoría Social \\ Trinidad L. Vicente Torrado \\ Universidad de Deusto \\ <trinidad.vicente@deusto.es>
}

\begin{abstract}
Jatorri askotariko herrialdeetatik iritsi da jendea gure gizartean bizitzeko, eta emakumezkoak izan dira etorritako horietatik guztietatik erdiak. Geroz eta gehiago nabarmentzen da emakumeen presentzia immigranteen elkarteen jardueran, eta protagonista izatearen analisia burutu dute artikulu honetan. Betiere, berauen ezaugarri nagusiak aztertu dituzte, eta honako hauek dira: banaketa geografikoa, egindako ibilbidea, berauen helburuak, eginkizunak, lorpenerako balizko bideak, eta berauen ekintzak eta esku-hartzeak baldintzatutako banakoen faktoreak eta testuinguruaren araberako faktoreak aztertu dituzte. Betiere, xedetzat hartu dute ia ikusezin izatetik gizarte-eragile izatera bilakatu daitezen, bai arlo sozialean bai politikoan ere; modu horretara, kontuan hartu beharko dituzte emakume immigranteak politika publikoak diseinatzerakoan, eta benetako gizarte interkulturala osatzeko bidean.
\end{abstract}

\section{HITZ-GAKOAK:}

immigranteen asoziazionismoa, emakumeak, hiritarren partaidetza, gizarteratzea, Euskadi.
Las mujeres inmigrantes conforman la mitad de la población llegada a la sociedad vasca desde otros países con el objeto de establecerse en ella. En este artículo, se trata de analizar su creciente protagonismo en el tejido asociativo inmigrante, prestando especial atención a sus principales características, su distribución geográfica, su trayectoria temporal, sus objetivos, actividades y vías para alcanzarlos, así como a los factores individuales y contextuales que determinan sus acciones e intervenciones. $Y$ todo ello con el objeto de visibilizarlas como agentes sociopolíticos que se han de tener en cuenta en el diseño de políticas públicas y en la conformación de una sociedad realmente intercultural, de la que también forman parte.

\section{Palabras clave:}

asociacionismo inmigrante, mujeres, participación ciudadana, integración, País Vasco. 


\section{Introducción}

La participación de las mujeres inmigrantes en la vida sociopolítica viene en buena medida determinada por su incorporación a las estructuras socioeconómicas y políticas, y por las oportunidades a su alcance en la sociedad de destino, por la duración y estabilidad de su residencia, por su posición en el interior de su propia comunidad y por los vínculos de estas comunidades con sus sociedades de origen. En este contexto, el objetivo de este artículo es poner de manifiesto el actual y creciente tejido asociativo liderado y desarrollado por la inmigración femenina en el País Vasco, así como los medios a través de los cuales estas mujeres intentan cuestionar y renegociar las actuales relaciones de poder en el interior de su hogar, de la comunidad y de la sociedad. Aunque muchas de las actividades y reivindicaciones de estas asociaciones comienzan a escala local (en un intento de ayudar a quienes acaban de llegar en su proceso de adaptación a sus nuevas condiciones de vida en la sociedad vasca, denunciando al mismo tiempo las condiciones precarias en las que frecuentemente se encuentran muchas mujeres, familias y comunidades inmigrantes), otra buena parte de sus actividades y reivindicaciones implican también conexiones a escala nacional e, incluso, internacional, lo que las convierte en protagonistas del denominado 'transnacionalismo desde abajo'.

Precisamente, en la elaboración de este artículo se han tenido muy en cuenta las entrevistas en profundidad realizadas a representantes de catorce asociaciones de mujeres inmigrantes en diciembre del 2010, en el marco de un proyecto promovido y financiado por la Dirección de Inmigración del Gobierno Vasco en los ámbitos de las migraciones y el desarrollo, desde una perspectiva de género. Dichas asociaciones, a quienes agradecemos sinceramente su participación, fueron: ASEMA, Arahma, Grupo de Mujeres Migradas de Getxo, Alnour, Mujeres en la Diversidad, Garaipen, Safa, Lacasiun, Mujeres del Mundo Unidas, Bidez-Bide, Voz-Colombia, Djelia Taama Musoo, Amalur Charrua y el Grupo de Mujeres Senegalesas.

\section{La inmigración femenina en el País Vasco: evolución y características}

Las mujeres que, procedentes de otros países, residen en el País Vasco a comienzos del 2010 ascienden a 83.640 , lo que supone que una de cada dos personas nacidas en el extranjero y empadronadas en los municipios vascos es mujer. A lo largo de la última década, y especialmente durante el último quinquenio, la inmigración femenina ha registrado una tendencia claramente creciente, siguiendo una pauta también exhibida por la población inmigrante masculina. Así, en los diez últimos años, las muje- res llegadas desde otros países han aumentado en un destacado $355 \%$, pasando de 18.393 en el momento del cambio de siglo, a 47.176 en el año 2005, y alcanzando las 83.640 a comienzos de 2010. Ahora bien, el equilibrio de sexos que exhibe en la actualidad la población inmigrante en el País Vasco y este crecimiento de la inmigración femenina en términos cuantitativos, especialmente en fechas recientes, no debe ocultar otra realidad: el predominio de las mujeres en los flujos migratorios hacia el País Vasco a lo largo de la década de los noventa y hasta el cambio de siglo (Vicente, 2006b). Tal y como reflejan los datos de empadronamiento correspondientes a 2000 , el $52 \%$ de las personas inmigrantes en esa fecha eran mujeres. En los años posteriores, su peso relativo se vio ligeramente reducido, situándose en torno al 50\%, debido al mayor crecimiento registrado por los hombres inmigrantes como resultado -al menos en partede los procesos de reagrupación familiar también llevados a cabo por ellas, y al reciente aumento experimentado por la inmigración de algunos colectivos nacionales claramente masculinizados. Por todo ello, el concepto de feminización de las migraciones, que se destaca como una de las principales características de los movimientos migratorios actuales no ha de reducirse a la consideración del aumento de las mujeres inmigrantes en términos cuantitativos, sino que exige una mayor apertura conceptual, que tenga en cuenta que los movimientos de población y sus impactos están profundamente 'generizados'.

Estas mujeres nacidas en otros países y afincadas en el País Vasco muestran, sin embargo, diferentes situaciones administrativas: $19.817(24 \%)$ ya se han nacionalizado españolas; 49.118 (59\%) cuentan con un permiso de residencia, bien sea en régimen general $(29.486,35 \%$ ) o comunitario (19.632, $24 \%$ ), mientras que 14.705 (17\%) se encuentran en situación irregular. Más de la mitad (51\%) de la inmigración femenina afincada en territorio vasco se encuentra en Bizkaia (40.872 mujeres), siendo éste además el territorio que presenta un mayor índice de feminización de su población inmigrante (hay un $51 \%$ de mujeres y un $49 \%$ de hombres). Gipuzkoa es el segundo territorio que registra un mayor número de mujeres originarias de otros países (25.741), que vienen a representar el 30\% del total registrado en el País Vasco. Y Álava, por su parte, se coloca en la tercera posición, con 14.952 mujeres, con el $18 \%$ del total de la inmigración femenina presente en tierras vascas. En Gipuzkoa, las mujeres representan la mitad de la población inmigrante total (25.741 mujeres frente a 25.578 hombres), mientras que Álava es la única provincia vasca en la que la presencia masculina supera a la femenina (con un registro de $\mathbf{1 7 . 2 9 2}$ hombres frente a $\mathbf{1 4 . 9 5 2}$ mujeres; es decir, que de cada 100 personas inmigrantes residentes en tierras alavesas, 54 son hombres, frente a 46 mujeres). 
Las tres capitales vascas son los municipios con mayor cantidad de mujeres inmigrantes. Bilbao, con 17.542 mujeres llegadas desde otros países, es el municipio vasco con mayor número de inmigrantes femeninas, seguido de Vitoria-Gasteiz (12.373) y Donostia-San Sebastián (8.629). En Bizkaia, después de su capital, los municipios con mayor inmigración femenina son: Getxo (3.703), Barakaldo (3.346), Leioa (1.176), Portugalete (1.121), Santurtzi (1.103), Durango (1.070), Sestao (976), Erandio (974), Basauri (939), Mungia (835) y Gernika-Lumo (800). En estos doce municipios, se ubican más de tres cuartas partes (78\%) de las mujeres procedentes de otros países residentes en este territorio histórico. En Álava, tan sólo seis municipios concentran el 91\% de las mujeres inmigrantes residentes: VitoriaGasteiz (12.373), Laudio/Llodio (453), Amurrio (312), Salvatierra/Agurain (237), Oyón-Oion (158) y AlegríaDulantzi (104). Y, por último, en Gipuzkoa, junto a Donostia-San Sebastián, son los municipios de Irun (3.087), Errenteria (1.171), Zarautz (911), Eibar (894), Pasaia (725), Lasarte-Oria (671), Hondarribia (613), Arrasate/Mondragón (596), Beasain (587), Hernani (547) y Ordizia (542) los que abarcan un mayor número de mujeres inmigrantes, ubicándose en ellos prácticamente tres cuartas partes de este colectivo (74\%).

Por continentes de origen, más de la mitad de la inmigración internacional femenina llegada al País Vasco procede del continente americano (58\%), seguido del europeo (26\%), el africano (11\%) y del asiático (5\%). De hecho, el continente americano es el que presenta el mayor índice de feminización migratoria en el País Vasco (con 59 mujeres de cada 100 personas de esta procedencia), seguido de los continentes europeo y asiático (ambos con 45 mujeres de cada 100 personas originarias de estos países), siendo el continente africano el que menor tasa de feminización exhibe (con apenas una mujer por cada dos hombres de esta procedencia).

Es interesante destacar las diferencias de esta distribución por principales áreas de origen, comparándola con la de los varones inmigrantes. Entre ellos, las nacionalidades americanas, aun siendo las primeras (representan un 40\% del total), no alcanzan el peso relativo que tienen en el caso de sus compatriotas mujeres. La inmigración masculina de origen europeo y, especialmente, de origen africano, presenta, por el contrario, un mayor peso relativo (un $31 \%$ y un $24 \%$, respectivamente, del total de hombres inmigrantes en el País Vasco) que la emigración femenina de esos lugares, mientras que en la inmigración masculina desde los países asiáticos se observa un peso relativo muy similar al registrado entre las mujeres inmigrantes de esta área geográfica (6\%). Por territorios históricos, las tasas de feminización de las poblaciones americanas, asiáticas y, sobre todo, europeas son ligeramente superiores en Bizkaia y Gipuzkoa respecto a Álava. En este último territorio, en cambio, la tasa de feminización de la población africana es superior a la registrada en Gipuzkoa y, sobre todo, en Bizkaia.

Tomando en cuenta las veinte principales nacionalidades de las mujeres inmigrantes empadronadas en el País Vasco a comienzos del 2010, observamos que éstas abarcan al $83 \%$ de este colectivo, tal y como se recoge en la Tabla 1. Dicho porcentaje es muy similar al que representan las primeras 20 nacionalidades en el conjunto de la población inmigrante, esto es, considerando no sólo a las mujeres, sino también a los hombres procedentes de otros países (80\%). Ello da buena idea de que, entre ellas, existe la misma diversidad de orígenes que entre ellos, siendo ésta precisamente otra de las principales características de los movimientos migratorios actuales.

Colombia, seguida a cierta distancia por Bolivia, son los dos principales países de origen de la población inmigrante femenina en el País Vasco. Ahora bien, entre las diez primeras nacionalidades encontramos otras cuatro de origen latinoamericano, como son la ecuatoriana ( $\left.4^{\mathrm{a}}\right)$, la brasileña (6 $\left.6^{\mathrm{a}}\right)$, o la paraguaya y la argentina ( $9^{\underline{a}}$ y $10^{-}$, respectivamente). Además, en los primeros puestos de esta lista logran colocarse tres nacionalidades europeas: la rumana ( $\left.3^{\underline{a}}\right)$, la portuguesa y la francesa ( $7^{\underline{a}}$ y $8^{\underline{a}}$, respectivamente). $Y$ aun estando la inmigración marroquí muy masculinizada, las mujeres procedentes de ese país africano logran alzarse al $5^{\circ}$ puesto, siendo la única nacionalidad de este continente entre las diez primeras.

La clasificación de principales nacionalidades varía, no obstante, de forma importante en los tres territorios históricos. Así, en Bizkaia el colectivo de mujeres inmigrantes está liderado por las originarias de Bolivia, seguidas de cerca por las procedentes de Colombia y, a mayor distancia, por las nacidas en Rumanía, Brasil, Paraguay, Ecuador, Marruecos, Francia, China y Venezuela. En Gipuzkoa, el primer colectivo de mujeres inmigrantes lo componen las procedentes de Colombia, seguidas en este caso por las llegadas desde Ecuador, Portugal, Rumanía, Marruecos, Francia, Nicaragua, Argentina, Brasil y Bolivia. Y en Álava, el ranking también está liderado por Colombia, seguida por Marruecos, Brasil, Ecuador, Rumanía, Argelia, Paraguay, Portugal, Perú y República Dominicana.

Según la encuesta que Ikuspegi, el Observatorio Vasco de Inmigración, realizó a la población extranjera en 2007, prácticamente dos tercios de las mujeres inmigrantes en el País Vasco (62\%) tienen estudios secundarios, profesionales medios 0 universitarios, que cursaron en sus países de origen -niveles de estudios superiores a su promedio nacional, lo que da cuenta de la selectividad de los procesos migratorios- y ligeramente más altos también a los exhibidos por los varones inmigrantes (Ikuspegi, 2009). 
Tabla 1. Principales orígenes nacionales de la inmigración femenina. País Vasco, 2010

\begin{tabular}{|c|c|c|c|c|c|}
\hline & $\begin{array}{l}\text { País } \\
\text { de origen }\end{array}$ & $\begin{array}{c}\text { Mujeres } \\
\text { inmigrantes }\end{array}$ & $\begin{array}{c}\text { \% sobre total } \\
\text { mujeres inmigrantes }\end{array}$ & $\begin{array}{c}\text { Total } \\
\text { inmigrantes }\end{array}$ & $\begin{array}{c}\% \text { mujeres por } \\
\text { nacionalidad }\end{array}$ \\
\hline 1 & Colombia & 10.172 & 12,2 & 17.295 & 58,8 \\
\hline 2 & Bolivia & 7.282 & 8,7 & 11.994 & 60,7 \\
\hline 3 & Rumanía & 6.892 & 8,2 & 14.378 & 47,9 \\
\hline 4 & Ecuador & 5.027 & 6,0 & 9.347 & 53,8 \\
\hline 5 & Marruecos & 4.901 & 5,9 & 14.667 & 33,4 \\
\hline 6 & Brasil & 4.531 & 5,4 & 6.697 & 67,6 \\
\hline 7 & Portugal & 3.501 & 4,2 & 9.905 & 35,3 \\
\hline 8 & Francia & 3.364 & 4,0 & 6.599 & 51,0 \\
\hline 9 & Paraguay & 3.295 & 3,9 & 4.639 & 71,0 \\
\hline 10 & Argentina & 3.009 & 3,6 & 6.058 & 49,7 \\
\hline 11 & China & 2.479 & 3,0 & 4.552 & 54,5 \\
\hline 12 & Perú & 2.222 & 2,7 & 4.183 & 53,1 \\
\hline 13 & Venezuela & 2.177 & 2,6 & 4.033 & 54,0 \\
\hline 14 & Cuba & 2.090 & 2,5 & 3.355 & 62,3 \\
\hline 15 & Rep. Dominicana & 1.923 & 2,3 & 2.886 & 66,6 \\
\hline 16 & Nicaragua & 1.823 & 2,2 & 2.320 & 78,6 \\
\hline 17 & Argelia & 1.469 & 1,8 & 4.475 & 32,8 \\
\hline 18 & Alemania & 1.254 & 1,5 & 2.599 & 48,2 \\
\hline 19 & México & 1.110 & 1,3 & 1.890 & 58,7 \\
\hline 20 & Chile & 1.065 & 1,3 & 2.074 & 51,4 \\
\hline \multicolumn{2}{|c|}{ Resto de países } & 14.054 & 16,8 & 33.436 & 42,0 \\
\hline \multicolumn{2}{|c|}{ Total } & 83.640 & 100,0 & 167.382 & 50,0 \\
\hline
\end{tabular}

Fuente: Elaboración propia a partir de los datos del Instituto Nacional de Estadística.

Estos niveles formativos no se corresponden, en cambio, con la situación laboral afrontada por estas mujeres dentro de la sociedad vasca. A comienzos del 2010, apenas una cuarta parte de las mujeres inmigrantes con permiso de residencia se encuentran en alta laboral en la Seguridad Social, aunque es bien conocida su frecuente incorporación al mercado de trabajo dentro de la economía sumergida. De hecho, este colectivo sólo representa el $41 \%$ de las altas laborales registradas por parte de la población extranjera, a pesar de tener un nivel educativo mayor que sus compatriotas varones, de que la mayoría de estas mujeres ya trabajaba en su país de origen, de su necesidad de un empleo que les garantice su propia subsistencia económica y la de sus familias, así como la obtención o la renovación de los preceptivos permisos para residir regularmente en esta sociedad.

Atendiendo al régimen de la seguridad social en el que se encuentran, un $31 \%$ (frente al $2 \%$ de los hombres extranjeros) se halla en el régimen especial de empleadas de hogar; porcentaje que en Bizkaia, el territorio más feminizado, alcanza el $35 \%$. Es éste un sector laboral caracterizado por una alta precariedad y en el que, además, se ubica la mayoría de las mujeres inmigrantes que trabajan en la economía sumergida. La presencia de estas mujeres en el régimen general (59\%) y en el de trabajadores autónomos $(8 \%)$ es, en cambio, comparativamente inferior a la registrada por los varones extranjeros $(72 \%$ y $16 \%$, respectivamente). Por otra parte, menos de la mitad de las mujeres extranjeras en alta laboral disfruta de un contrato indefinido (5.847, frente a las 6.167 que tienen un contrato temporal), siendo además sus contratos, en la mayoría de los casos, a tiempo parcial (un $52 \%$, frente al $48 \%$ que dispone de un contrato a jornada completa). Esta precaria incorporación al mercado de trabajo remunerado, claramente marcada por la construcción social del género, limita en buena medida las oportunidades de promoción laboral, así como la valoración social y las posibilidades de participación sociopolítica de este creciente colectivo de mujeres, inmigrantes y trabajadoras en la sociedad vasca (Vicente, 2006a).

Por último, en este apartado conviene apuntar que, según los datos de Ikuspegi, únicamente el $9 \%$ de las mujeres inmigrantes en el País Vasco afirman pertenecer a alguna asociación, siendo preferente en estos casos la opción por organizaciones de personas originarias del mismo país, frente a otro tipo de entidades, como las asociaciones de inmigrantes de cualquier país, las asociaciones de apoyo a inmigrantes, los partidos políticos o los sindicatos (Sáez de la Fuente, 2008). Precisamente, vamos a dedicar los siguientes apartados de este artículo a profundizar en el conocimiento del entramado asociativo conformado y liderado por estas mujeres inmigrantes.

\section{La autoorganización de las mujeres inmigrantes en el País Vasco}

La acción colectiva de las mujeres inmigrantes al margen de los espacios mixtos ha recibido escasa atención por parte de los agentes públicos y privados de los ámbitos de la inmigración y la igualdad en el País Vasco. En general, se observa una tendencia a abordar el asociacionismo inmigrante de origen extranjero sin reparar en el papel activo que están cumpliendo las propias mujeres, tanto dentro de los espacios mixtos como de los espacios creados y formados por ellas mismas. Algo que contras- 
ta, como hemos visto anteriormente, con el importante volumen de población extranjera femenina presente en el País Vasco, especialmente entre determinados grupos nacionales procedentes de Latinoamérica. Aun así, y a pesar de que no se hayan realizado, hasta el momento, estudios que analicen cuantitativamente la participación asociativa de las mujeres inmigrantes en el País Vasco, sabemos que ellas superan en número a los hombres en varias asociaciones mixtas de origen latinoamericano, así como en alguna de origen asiático (como es el caso de la conformada por personas de origen filipino). Ahora bien, sería interesante analizar en qué medida la mayor representación femenina en dichas asociaciones se corresponde con una mayor participación de las mujeres en los órganos de toma de decisiones, y con la consideración de sus propuestas por parte de los hombres en estos mismos órganos. De hecho, como veremos más adelante, las reticencias del colectivo masculino a compartir los espacios de poder con las mujeres es uno de los factores que las está motivando a crear sus propias organizaciones. Y es precisamente este proceso de autoorganización lo que vamos a tratar seguidamente.

Primero, queremos aclarar que entendemos como asociación de mujeres inmigrantes aquella que ha sido creada y está formada por mujeres, y en la que la mitad de su Junta directiva, o al menos la mitad de sus socias, son mujeres de origen extranjero. Igualmente, también tomamos en consideración los grupos de mujeres que, por el momento, no se han constituido formalmente como asociación, aunque están en proceso de hacerlo.

Antes de adentrarnos en los motivos que impulsan el asociacionismo de las mujeres inmigrantes, vamos a exponer brevemente sus elementos más característicos en torno a su distribución geográfica, trayectoria temporal y composición por nacionalidades. El volumen de asociaciones activas con las características descritas asciende a dieciséis, y su distribución geográfica se corresponde con la de la población inmigrante femenina en el País Vasco. De tal manera, casi la mitad de estas organizaciones se sitúan en Bizkaia (7), a la que siguen, en este sentido, Gipuzkoa (5) y Álava (4). La vida asociativa de la mayoría de ellas no supera los cinco años de antigüedad, algo que puede considerarse lógico si tenemos en cuenta que, por un lado, el mayor crecimiento en las llegadas de población femenina extranjera tiene lugar precisamente en esta última década, y, por otro, que la participación activa en espacios colectivos requiere de una mínima estabilidad vital, que normalmente sólo se consigue transcurridos unos años desde la llegada. No obstante, cabe señalar que el cálculo de la antigüedad asociativa se ha realizado según la fecha de su inscripción en el registro oficial de asociaciones y que, en general, suele haber un periodo pre- vio de uno o dos años durante el cual las mujeres se reúnen sin estar constituidas formalmente como asociación.

\begin{tabular}{|c|c|}
\hline \multirow[t]{7}{*}{ Bizkaia (7) } & $\begin{array}{l}\text { Asociación de Solidaridad entre las Mujeres Angole- } \\
\text { ñas, ASEMA, (1997, Bilbao) }\end{array}$ \\
\hline & Asociación 'Mujeres del Mundo Babel’ (2000, Bilbao) \\
\hline & $\begin{array}{l}\text { Asociación de Mujeres Jóvenes Musulmanas ‘Bidaya’ } \\
(2007, \text { Bilbao) }\end{array}$ \\
\hline & Asociación ‘Mujeres en la Diversidad’, (2007, Basauri) \\
\hline & $\begin{array}{l}\text { Asociación de Mujeres Vasco-árabes ‘Arahma’ } \\
(2009, \text { Getxo) }\end{array}$ \\
\hline & Grupo de Mujeres Migradas de Getxo (2010, Getxo) \\
\hline & $\begin{array}{l}\text { Asociación de Mujeres Musulmanas ‘Alnour’ } \\
\text { (2010, Durango) }\end{array}$ \\
\hline \multirow[t]{5}{*}{ Gipuzkoa (5) } & $\begin{array}{l}\text { Asociación de Mujeres Inmigrantes y Vascas ‘Garai- } \\
\text { pen’ (2002, Errenteria) }\end{array}$ \\
\hline & $\begin{array}{l}\text { Asociación de Mujeres Inmigrantes ‘Malen Etxea’ } \\
(2003, \text { Zumaia) }\end{array}$ \\
\hline & $\begin{array}{l}\text { Asociación de Mujeres Árabe-musulmanas ‘Safa' } \\
\text { (2006, Eibar) }\end{array}$ \\
\hline & $\begin{array}{l}\text { Asociación de Mujeres Latinas ‘Lacasiun’ } \\
\text { (2007, Eibar) }\end{array}$ \\
\hline & $\begin{array}{l}\text { Asociación ‘Mujeres del Mundo Unidas’ } \\
\text { (2010, Donostia-San Sebastián) }\end{array}$ \\
\hline \multirow{5}{*}{$\begin{array}{l}\text { Araba-Álava } \\
\text { (4) }\end{array}$} & Asociación Sociocultural de Mujeres Inmigrantes 'Voz \\
\hline & Colombia’ (Vitoria-Gasteiz) $^{1}$ \\
\hline & $\begin{array}{l}\text { Asociación Intercultural de Mujeres Africanas y Vas- } \\
\text { cas ‘Djelia Taama Musoo’ (2007, Vitoria-Gasteiz) }\end{array}$ \\
\hline & $\begin{array}{l}\text { Asociación Sociocultural de Mujeres por Latinoaméri- } \\
\text { ca ‘Amalur Charrua' (2008, Vitoria-Gasteiz) }\end{array}$ \\
\hline & $\begin{array}{l}\text { Grupo de Mujeres Senegalesas } \\
(2008, \text { Vitoria-Gasteiz) }\end{array}$ \\
\hline
\end{tabular}

Fuente: Elaboración propia.

Por lo que se refiere a la composición de las asociaciones según el origen de las socias, se observa una tendencia al agrupamiento plurinacional en torno a grandes grupos geográficos. Son muy pocos los casos en los que las asociaciones concentran únicamente a socias de una misma nacionalidad. Así, por ejemplo, las mujeres procedentes del Magreb tienden a juntarse con otras mujeres procedentes del norte de África, al igual que ocurre con las migrantes de otros países subsaharianos y con las latinoamericanas. Varias asociaciones albergan entre sus miembros, asimismo, a mujeres autóctonas y de origen extranjero. Esta realidad choca con la idea, ampliamente extendida, de que las personas inmigrantes solamente se asocian con otras de su mismo grupo nacional, pero resulta lógica si tenemos en cuenta varios aspectos, como pueden ser los problemas comunes que tienen que afrontar como inmigrantes (agravados por las desigualdades de género), o la escasa militancia que,

${ }^{1}$ La asociación 'Voz-Colombia' surgó como asociación mixta en 2004, y se constituyó como asociación de mujeres en febrero de 2010.

2 El Grupo de Mujeres Senegalesas surgió dentro de la Asociación de Senegaleses de Álava ‘Mboolo-Elkar', creada en 2006. 
como ya hemos destacado anteriormente, registra este colectivo, muchas veces aduciendo escasez de tiempo para hacer frente a sus responsabilidades laborales y familiares (aunque quizá el compromiso asociativo no sea mucho mayor en términos relativos entre las mujeres autóctonas). Además, la reducida presencia de algunos grupos nacionales en el País Vasco, como por ejemplo, los de Burkina Faso o Mali, puede estar contribuyendo a que gran parte de las asociaciones tiendan a estar formadas por personas de una misma área geográfica, como es el caso del África Subsahariana. Esta diversidad nacional presente entre las asociaciones de mujeres inmigrantes se ha observado, igualmente, entre asociaciones similares a escala europea (Lenz y Schwenken, 2002) y entre las asociaciones de inmigrantes masculinas, o mixtas, a escala provincial (Unzueta y Di Carlo, 2010) y estatal (Aparicio y Tornos, 2010).

Esta breve descripción nos ha servido para hacer una fotografía general del asociacionismo de las mujeres inmigrantes. Sin embargo, es preciso ir más allá para tratar de comprender su origen en el País Vasco. Un origen que está influenciado por factores individuales y contextuales que interactúan entre sí, y cuyo peso varía de una asociación a otra. Los primeros engloban la diversidad existente entre las mujeres inmigrantes como personas con una trayectoria y un proyecto vital únicos, que, en interacción con un determinado contexto, pueden activar 0 reforzar su dimensión social en espacios colectivos organizados. Hablamos, entre otros, de factores individuales como la edad, el sexo, la clase social, el nivel educativo o el sentido vital. Si a ellos les añadimos los contextos de origen y de destino, la comprensión de los motivos por los que surgen las asociaciones se torna más compleja, pero también más ajustada a la realidad.

En este artículo, queremos centrar la atención en factores del contexto del País Vasco que motivan a las mujeres inmigrantes a implicarse en la organización de sus propios espacios, para lo cual es preciso empezar considerando las oportunidades reales que las mujeres encuentran en la sociedad de destino para desarrollar su proyecto de vida según sus necesidades, deseos e intereses, o de acuerdo exclusivamente con las necesidades de la sociedad a la que llegan. Así, por ejemplo, la restringida y frecuentemente precarizada oferta laboral dirigida al colectivo femenino de origen inmigrante (centrada, en buena medida, en el mencionado sector del servicio doméstico y de cuidados personales), deja, en muchos casos, a las mujeres inmigrantes en situaciones de explotación y exclusión social (Vicente, 2006a). De hecho, la forma en que tiene lugar la inserción de estas mujeres en el mercado de trabajo del País Vasco es un factor clave del contexto que las incita a asociarse con el objeto de prestarse ayuda mutua y de conformar una red social que contribuya a su movilidad laboral ascendente, pero también de denunciar situaciones de explotación a las que están sometidas muchas de las que trabajan en el sector servicios, y de reclamar sus derechos laborales. Asimismo, el proceso migratorio conlleva una serie de cambios y adaptaciones cuya vivencia varía de persona a persona, en función de factores individuales, pero también de los medios de apoyo disponibles en la sociedad de destino. Así, otro factor del contexto vasco que, en general, ha motivado la creación de asociaciones de mujeres inmigrantes ha sido la necesidad de llenar vacíos en los servicios facilitados por las instituciones públicas y privadas en relación con problemáticas asociadas al propio proceso migratorio.

En definitiva, los factores del contexto de destino hacen que la diversidad existente entre el colectivo femenino inmigrante converja en espacios comunes desde los que afrontar las dificultades derivadas del proceso migratorio por su condición de mujeres e inmigrantes. Precisamente, esta doble condición nos conduce a otros motivos, que responden, en parte, al por qué han ido surgiendo grupos de mujeres inmigrantes al margen de las asociaciones de inmigrantes mixtas y de las asociaciones de mujeres autóctonas. Por un lado, la mirada de género nos alerta sobre las normas socioculturales que guían el funcionamiento interno de muchas asociaciones de inmigrantes y que, en última instancia, impiden la participación de las mujeres en igualdad de condiciones con los hombres (aunque cabe señalar que esta desigual participación varía según el origen geográfico y etnocultural predominante en las asociaciones). Por otro lado, y en relación con las asociaciones de mujeres autóctonas, las múltiples discriminaciones que sufren las mujeres por razón de su origen y, en general, por su estatus de inmigrantes contribuyen a que opten por crear nuevos espacios en los que poder responder a las problemáticas y demandas específicas asociadas a la migración. Espacios a los que también se unen otras mujeres autóctonas, porque, a pesar de las distintas necesidades de unas y otras según su origen y momento vital, existe un elemento común a todas ellas, su condición de mujer, que muchas veces las aboca a situaciones de marginación y exclusión. De hecho, el encuentro entre mujeres de diferentes orígenes a menudo sucede con motivo de la celebración de actividades proigualdad de género, como charlas, talleres y marchas para la reivindicación de los derechos de las mujeres y contra la violencia de género. Actividades que, en algunos casos, desencadenan procesos de autoorganización entre las mujeres, como ha sucedido con el Grupo de Mujeres Migradas de Getxo. En definitiva, los motivos que inducen a las mujeres a asociarse y a crear sus propias organizaciones son múltiples y, a menudo, interactúan entre sí. 


\section{Diversidad en la autoorganización: aspectos comunes y particularidades}

\subsection{Origen, objetivos y actividades}

La diversidad a la que nos hemos referido anteriormente para hablar de las mujeres inmigrantes como personas con trayectorias y proyectos vitales únicos cabe aplicarla igualmente a las formas que ellas mismas otorgan a sus aspiraciones de organización y acción colectiva. El resultado de esta diversidad individual, siempre en el marco de un contexto que moldea lo particular, se refleja en la variedad de asociaciones de mujeres inmigrantes que existen en el País Vasco, tanto por los objetivos específicos que persiguen como por las vías que utilizan para alcanzarlos. Ahora bien, si nos movemos de lo concreto a lo general, podemos observar que todas iniciaron su andadura con el objetivo común de mejorar las condiciones de vida de las mujeres inmigrantes en general y, concretamente, según el caso y las necesidades, de las mujeres de una misma identidad etnocultural. Empezaron organizándose para responder a las necesidades prácticas que tenían las mujeres por su condición migratoria atravesada por el género, y la amplia mayoría mantiene su acción colectiva centrada, sobre todo, en dar respuesta a esas necesidades. Ahora bien, también se ha observado una evolución en la estrategia asociativa de algunas de ellas, que combinan la acción social con la acción política, llegando incluso, en algún caso, a priorizar esta última frente a una acción social, que consideran es responsabilidad del Estado.

Desde la perspectiva de género, puede afirmarse que gran parte de las asociaciones de mujeres inmigrantes activas en el País Vasco están actuando en el terreno de las necesidades prácticas de género, es decir, de las que surgen de los roles que tradicionalmente se les han asignado a las mujeres y de su posición subordinada en la sociedad. Estamos hablando, por ejemplo, del importante papel que cumplen como espacios de ayuda mutua para atender a las problemáticas derivadas del trabajo en el servicio doméstico y de cuidados, de la violencia machista intra y extrafamiliar, de la salud sexual y reproductiva, de la maternidad en la distancia, del analfabetismo en los idiomas de las sociedades de origen y de destino, o del aislamiento doméstico, entre otras. Sin embargo, son pocas las que están centrando su esfuerzo colectivo en atender a las necesidades estratégicas de género (Molyneux, 1985), que tienen que ver con la superación de los elementos que mantienen a las mujeres en una posición de subordinación frente a los hombres. Son necesidades estratégicas de género, por ejemplo, la abolición de la división sexual del trabajo, la eliminación de formas institucionalizadas de discriminación, el control por parte de las mujeres de su propio cuerpo, o el alivio de la carga del trabajo doméstico y del cuidado de la prole.
Esta mayor tendencia de las asociaciones a actuar en el terreno de lo práctico proviene de factores como los que se han mencionado en el apartado anterior, pero además debe tenerse en cuenta que el contexto sociocultural de referencia de las propias mujeres también influye en la definición de los intereses estratégicos de género en el ámbito asociativo. Pongamos como ejemplo a las asociaciones creadas y formadas por mujeres de origen africano. Estas mujeres proceden de países con culturas caracterizadas por un fuerte componente patriarcal y cuya migración, en muchos casos, está ligada a la reagrupación familiar realizada por el esposo. La interacción de ambos elementos, la cultura patriarcal y la migración femenina como seguidora pasiva de los varones pioneros del proyecto migratorio, hacen que la participación asociativa de muchas mujeres africanas esté supeditada al permiso de los hombres y condicionada a la participación en actividades que perpetúen su rol social y sean 'neutras' respecto a las reivindicaciones de igualdad de género. De ahí que estas asociaciones, al igual que ocurre con algunas formadas por mujeres musulmanas, dirijan sus actividades principalmente a responder a las necesidades prácticas de las mujeres, optando por no manifestar explícitamente posicionamientos feministas como grupo, aunque ello en absoluto signifique una renuncia a ellos. Si se mira con cierta distancia, esta forma de actuar colectivamente puede constituir, en sí misma, una estrategia de las propias mujeres para ir avanzando en la lucha por la igualdad de género, tanto en el interior de su propio grupo etnocultural de referencia como dentro de la diversa sociedad vasca, considerada en su conjunto.

Sin perder de vista lo anterior, vamos a tratar de agrupar los principales objetivos específicos de las asociaciones y de exponer las actividades que realizan para lograrlos. Uno de los más extendidos es servir de espacio de encuentro y apoyo para las mujeres inmigrantes que, en función de las posibilidades de cada asociación, se materializa en apoyo psicológico, orientación jurídica, laboral y formativa, o en actividades de ocio y tiempo libre. Unas veces, este apoyo lo prestan las propias socias, y otras, cuando la situación lo requiere, éstas actúan como intermediarias ante instituciones públicas y privadas. En general, tal y como se viene mencionando, prevalecen las actividades de tipo social en sentido amplio y, obviamente, cambian de asociación a asociación, según las necesidades priorizadas por las mujeres que las conforman.

Si tomamos como muestra las actividades formativas, se observa que las prioridades en este ámbito son distintas entre las asociaciones formadas en su mayoría por mujeres de habla hispana, y las compuestas sobre todo por mujeres de habla no hispana. Estas últimas tratan de orientar su formación, aun con muchas dificultades, a la enseñanza del castellano y del idioma de origen de las socias, ya 
que entienden que las instituciones públicas no están respondiendo suficientemente a la demanda existente en este ámbito. Por ejemplo, la enseñanza del árabe es una de las actividades principales de las asociaciones de mujeres árabe-musulmanas, que no sólo contribuye al mantenimiento de la identidad cultural de su socias, sino que, además, en el caso de las personas analfabetas, constituye un paso previo importante en el aprendizaje de otro idioma, como es el castellano. Este tipo de formación es clave para el empoderamiento de las mujeres y para su integración en el País Vasco, ya que el analfabetismo en los idiomas de los lugares de origen o de destino condiciona, en buena medida, la autonomía de las mujeres y su participación como ciudadanas de pleno derecho en la sociedad (Vicente, 2003).

La prioridad que estas asociaciones otorgan al aprendizaje de los idiomas considerados básicos para el desarrollo de la vida cotidiana se combina con la organización de charlas y talleres para la mejora de la inserción sociolaboral. Actividades estas últimas a las que también se dedican varias asociaciones constituidas en su mayoría por mujeres latinoamericanas, y a las que se suman, además, otras acciones más directamente relacionadas con la formación feminista, o con la reflexión sobre las desigualdades de género en diferentes ámbitos y materias. Otro tipo de actividades bastante común entre las asociaciones son las relacionadas con el disfrute del ocio y tiempo libre, como las excursiones culturales y los eventos lúdico-festivos. Las primeras se organizan con el fin de conocer el contexto donde viven las mujeres y fomentar el conocimiento mutuo, mientras que las segundas constituyen una forma de socialización y encuentro, y en muchos casos se aprovechan para trasladar información sobre temas de interés para las mujeres. En términos generales, estas actividades que llevan a cabo las asociaciones en los ámbitos social, formativo y lúdico cumplen una importante función en el proceso de integración de las mujeres, al tratar de abordar las problemáticas derivadas de la migración y de las desigualdades de género, así como de acompañarlas en la búsqueda de respuestas a sus necesidades.

Otro de los objetivos que se plantea este tejido asociativo es el logro de una sociedad culturalmente diversa y cohesionada, para lo cual lleva a cabo actividades de educación y sensibilización sobre temas relacionados con la realidad migratoria de las mujeres y las culturas de origen de las socias, como son exposiciones, charlas, vídeodocumentales, cursos de cocina internacional, teatro, eventos musicales y de danza, y ferias, entre otras. Cabe destacar que algunas asociaciones se están sirviendo de espacios formales, como la escuela, para desarrollar su labor de sensibilización en este ámbito.

Orientar su acción colectiva al desarrollo de los lugares y las comunidades de origen de las socias es otro objetivo que está muy presente en gran parte de las asociaciones consideradas. En este sentido, algunos ámbitos en los que se plantean intervenir son la migración y la familia, la violencia de género, la educación, la salud sexual y reproductiva, la generación de ingresos entre las mujeres, o la articulación de redes transnacionales entre asociaciones de mujeres. Algunas de ellas ya están realizando proyectos en esta línea, aunque la gran mayoría admite que necesita apoyo técnico y financiero para poner en marcha las propuestas de este tipo. Más allá de la mayor o menor implicación que, hasta el momento, puedan estar teniendo estas asociaciones en el desarrollo de sus sociedades de origen, debe tenerse en cuenta que su actividad transnacional es clave para actuar sobre las causas y efectos de los procesos migratorios y de desarrollo desde la perspectiva de género (Unzueta, 2009).

En resumen, todas estas organizaciones sociales persiguen promover la participación asociativa de las mujeres, para asegurar su inclusión en redes femeninas de apoyo que mejoren su autoestima y fomenten su autonomía personal. Puede decirse que todas ellas se dirigen al fin último de garantizar la participación de las mujeres como ciudadanas de pleno derecho en la sociedad. Sin embargo, mientras que una gran parte se centra en las actividades sociales mencionadas más arriba como pasos previos para lograrlo, otras pocas también están dirigiendo sus esfuerzos a acciones de carácter más político, que incluyen la reivindicación de los derechos de las mujeres, en general, y de las mujeres inmigrantes, en particular, y la promoción de su participación sociopolítica desde una conciencia feminista. El desigual énfasis que unas y otras ponen en la acción política parece estar relacionado con los diferentes niveles de empoderamiento individual que viven las mujeres inmigrantes, así como con la trayectoria personal de cada una de ellas previa a la migración y la presión patriarcal del grupo etnocultural de referencia.

\subsection{Funcionamiento asociativo hacia dentro y hacia fuera}

La variedad de asociaciones de mujeres inmigrantes a la que nos hemos referido anteriormente adquiere mayor relevancia, si cabe, cuando nos detenemos en las formas organizativas y de funcionamiento que constituyen el marco a partir del cual desarrollan sus actividades. Si bien todas ellas están registradas como asociación, o en proceso de hacerlo, y por lo tanto, cuentan con una estructura formal de funcionamiento característica de la sociedad de destino, en la práctica tienden a regirse por dinámicas más acordes con su propia forma de hacer cultural y recursos disponibles. De hecho, hay asociaciones que, a pesar de contar con escasos recursos económicos, están desarrollando su labor asociativa en el 
marco de redes informales de apoyo que muchas veces resultan invisibles a los ojos de quienes están fuera de este entramado. Y es a través de estas redes como consiguen llegar a mujeres que, por motivos como los que veremos más adelante, no pueden participar activamente en la asociación, y para quienes dicho apoyo constituye un soporte fundamental para integrarse.

Sin embargo, el asunto de los recursos nos lleva a hablar sobre la debilidad institucional que presentan gran parte de las asociaciones y que, a menudo, no les permite emprender y gestionar proyectos que contribuirían al logro de todos sus objetivos. Debilidad que, en general, caracteriza al asociacionismo inmigrante de origen extranjero en el País Vasco, así como en el resto del Estado (Aparicio y Tornos, 2010), y que tiene que ver, en parte, con la escasez de recursos financieros y humanos. Si atendemos a estos últimos, se observa que, con independencia del número de socias, las asociaciones funcionan gracias al esfuerzo y compromiso de un pequeño grupo de ellas, compuesto por entre tres y diez mujeres.

Entre otros motivos, el activismo de las mujeres inmigrantes se ve limitado por los obstáculos comunes que tienen que afrontar como consecuencia de su condición migratoria y de las desigualdades de género imperantes en la sociedad de destino y en el interior de su grupo etnocultural de referencia. Paradójicamente, los factores del contexto de destino que exponíamos al principio del artículo como desencadenantes del surgimiento de las asociaciones son los que, al mismo tiempo, están limitando el desarrollo de su acción colectiva. Como sabemos, la tradicional división sexual del trabajo que aún pervive en las sociedades receptoras ha abocado a gran parte del colectivo femenino de origen inmigrante a un sector de trabajo desvalorizado social y económicamente, lo cual, lejos de facilitar su integración, disminuye las oportunidades de desarrollar su proyecto migratorio más allá de un ámbito laboral precarizado. Igualmente, la tradicional división de roles de las sociedades de donde proceden las mujeres, que posteriormente se reproduce en la sociedad de destino -en mayor o menor grado, según los colectivos-, determina sus posibilidades de participación en las asociaciones y en la vida sociopolítica en general, especialmente en aquellos casos en los que ellas han sido reagrupadas por sus esposos y su identidad femenina está ligada al ámbito de la reproducción, el cuidado familiar y el trabajo doméstico.

Las discriminaciones de género también tienen su reflejo en el apoyo financiero que las instituciones públicas y privadas dan a los programas específicamente diseñados para luchar a favor de la igualdad de género y, entre ellos, a las asociaciones de mujeres. De acuerdo con los resultados de un estudio sobre el papel de las instituciones financiadoras en la promoción de los derechos de las mujeres y en el apoyo a las organizaciones que trabajan en este ámbito (Clark, Sprenger y Veneklasen, 2006), la tendencia a escala internacional ha sido el recorte de los fondos destinados a las asociaciones de mujeres y a las acciones en defensa de los derechos de este colectivo.

A las dificultades

burocráticas para

presentarse a convocatorias de subvenciones, se

\section{suma el desconocimiento de las posibles vías de financiación}

En el caso de las asociaciones de mujeres inmigrantes en el País Vasco, hay que añadir las dificultades técnicas que, a menudo, tienen para cumplir con los requisitos burocrático-administrativos exigidos por las instituciones a la hora de presentarse a convocatorias públicas de subvenciones y el desconocimiento que, en algunos casos, existe sobre las posibles vías de financiación públicas y privadas. Sólo una pequeña parte ha conseguido acceder a fondos públicos, principalmente a través de las áreas de Igualdad, a escala local, provincial y autonómica y, en menor medida, de otras áreas, como Inmigración. Pero, en general, es a través de fondos propios que están consiguiendo mantenerse, aún con muchas dificultades, puesto que el compromiso de las socias con las cuotas es inconstante, y las actividades generadoras de ingresos como mucho sirven para sufragar gastos de mantenimiento y acciones muy puntuales.

El éxito limitado en la recaudación de fondos públicos y propios se explica, en parte, por el actual contexto de crisis económica y el recorte general de presupuesto por el que han optado las instituciones públicas y, por otro lado, cabe relacionarlo con las propias socias y el estado de su economía doméstica. Cabe señalar que muchas mujeres cabeza de familia que han migrado para el sostenimiento del grupo familiar en origen y que, con mucho esfuerzo, consiguen recaudar dinero para enviarlo pueden vivir la aportación de una cuota con un sentimiento de culpa por 'privar' a sus familiares de un dinero necesario para su mantenimiento. Este aspecto que está ligado a las mayores expectativas puestas en las mujeres para el cumplimiento de las responsabilidades familiares y que, en muchas ocasiones, provocan en ellas conflictos internos asociados a la identidad de género. 
Se observa una enorme necesidad y demanda de apoyo para la búsqueda y captación de recursos, así como para el desarrollo de habilidades más técnicas que les permitan formular los proyectos de acuerdo con las exigencias tecnoburócratas, que no políticas, de las entidades financiadoras. Varias asociaciones viven en estado de resistencia, tratando de sobrevivir en un clima de recortes presupuestarios generalizados y en un contexto en el que, a menudo, no se valora en su justa medida el papel que cumplen para el desarrollo del proyecto vital de las mujeres. Su papel como agentes clave para la integración sociopolítica de la población femenina inmigrante ya lo señaló Sipi (2000) en su análisis sobre el asociacionismo de mujeres inmigrantes en Barcelona, quien también se refirió a la experiencia del trabajo en red entre las propias asociaciones como un paso importante para actuar colectivamente en el diseño de políticas públicas que afectan a las mujeres inmigrantes. Quizás, la articulación de una red entre las asociaciones de mujeres inmigrantes en el País
Vasco sea una estrategia que se ha de tener en cuenta para que su trabajo asociativo sea reconocido social y políticamente, y puedan seguir desarrollando su labor, ya no desde la supervivencia y resistencia, sino desde la certidumbre de que, en su lucha por la integración de las mujeres y la igualdad de género, tienen el apoyo de la sociedad receptora $y$, por supuesto, de sus instituciones públicas.

En definitiva, la alianza más fuerte entre las asociaciones de mujeres inmigrantes del País Vasco podría derivar en una agenda política común en torno al proceso de integración y a la igualdad de género que, por una parte, las visibilizara como agentes sociopolíticos dignos de tener en cuenta en el diseño de políticas públicas y, por otra, las situara en una mejor posición para acceder a financiación pública y privada. Esta alianza constituye una ardua labor, pero es viable si se hace una apuesta común por centrarse en lo que las une como mujeres y como miembros activos de esta sociedad. 


\section{Bibliografía}

APARICIO GÓMEZ, R.; y TORNOS, A. (2010): Las asociaciones de inmigrantes en España. Una visión de conjunto, serie Documentos del OPI, $\mathrm{n} 026$, Madrid, Ministerio de Trabajo e Inmigración.

CLARK, C.; SPRENGER, E.; y VENEKLASEN, L. (2006): ¿Dónde está el dinero para los derechos de las mujeres? Una evaluación sobre los recursos y el papel de las financiadoras en la promoción de los derechos de las mujeres y el apoyo a las organizaciones que trabajan por los derechos de las mujeres, Toronto; Washington DC, Association for Women's Rights in Development; Just Associates [<http://awid.org/esl/content /download/23392/305464/file/1st_fundher_ report_sp.pdf)].

IKUSPEGI (2009): Género e inmigración en la CAPV 2007, serie Panorámica de la Inmigración, $n-26$, Bilbao, Ikuspegi [<http://www.ikuspegi.org/ documentos/documentos_internos/ panoramica26cas.pdf)].

LENZ, I.; y SCHWENKEN, H. (2002): “Feminist and migrant networking in a globalising world. Migration, gender and globalisation", en LENZ, I. et al., Crossing Borders and Shifting Boundaries, vol. II, págs. 147-178.

MOLYNEUX, M. (1985): “Mobilization without Emancipation? Women's Interests, State and Revolution in Nicaragua", Critical Social Policy, vol. 4, nํㅜ 1, págs. 59-75. Issue 10.

SÁEZ DE LA FUENTE, I. (2008): Género e inmigración. Encuesta de Ikuspegi a la población extranjera 2007, colección Ikusgai, Vitoria-Gasteiz, Gobierno Vasco [<http://www.ikuspegi.org/documentos/ investigacion/es/2ikusgai_genero_inmigracion _ikuspegi.pdf $\rangle$.

SIPI, R. (2000): "Las asociaciones de mujeres, ¿agentes de integración social?", Papers, n으, 60, págs. 355-364.

UNZUETA SESUMAGA, A. (2009): “Asociacionismo de mujeres inmigrantes latinoamericanas y codesarrollo en el País Vasco: condicionantes y posibilidades", Cuadernos Bakeaz, no9 95, Bilbao (Serie Movimientos Sociales).

UNZUETA SESUMAGA, A.; y DI CARLO, M. G. (2010): Estudiodiagnóstico sobre las asociaciones de inmigrantes de origen extranjero en Bizkaia, Bilbao, Bakeaz [<http://ficheros.bakeaz.org/ Informe_final_asoc_inmigrante.pdf〉].

VICENTE TORRADO, T. L. (2006a): “Mujeres, género y migraciones internacionales: una realidad por redefinir", en Memoria del Congreso Internacional sobre los Derechos Humanos de las Mujeres Migrantes: acciones para su protección, México DF, Secretaría de Relaciones Exteriores; Fondo de Desarrollo de las Naciones Unidas para la Mujer, págs. 75-91.

- (2006b): “Caracterización de las mujeres extranjeras en la CAPV", en VV.AA. Mujeres inmigrantes, viajeras incansables, Bilbao, Harresiak Apurtuz, págs. 137-152.

- (2003): “España: 'país de inmigración femenina”, Letras de Deusto, vol. 33, № 99, págs. 137-172. 
